\title{
EL DOCENTE INVESTIGADOR: SU GÉNESIS TEÓRICA Y SUS RASGOS
}

\author{
Natalia Campos Saborío \\ Recibido 10-V-2003 \\ - Aceptado 10-VI-2003
}

\begin{abstract}
Resumen: El propósito de este artículo es enunciar los rasgos que caracterizan al docente investigador. Para ello, me ubico en el contexto teórico, desde dónde conceptualizo sus calidades, a saber: visión de mundo, de paradigma curricular, y de investigación educativa.
\end{abstract}

Palabras clave: Investigación Cualitativa, Docencia, Perfil del Docente Investigador.

\section{Introducción}

Como breve antecedente a la temática del docente investigador y su influencia en la calidad de los procesos de enseñanza y aprendizaje, abordamos, primero algunos hallazgos de cómo se perciben los futuros y las futuras maestras como docentes, y cuál es el perfil del docente en su diario quehacer en el aula.

Los futuros candidatos a docentes, según resultados del proyecto "Validación de un módulo de selección de candidatos a docentes", de las investigadoras Ana Teresa León, Ana María Hernández, Susana Ruiz e Irma Zuñiga de la División de Educación Básica del C.I.D.E., Universidad Nacional, se miran como personas que deben establecer "buenas relaciones con los otros. " (León y otros, 2002). La mayoría de los docentes (60\% de sus respuestas) expresan frases tales como: "querer a mis alumnos ... ser comprensiva... dar felicidad ...” (León y otros 2002). Otros docentes dan respuestas (29\% de ellas) relacionadas con el proceso enseñanza-aprendizaje, algunas de sus frases son: "que los niños ...aprendan bien ... bastante ...” y las maestras "enseñen adecuadamente... entreguen todos sus conocimientos...". Un grupo minoritario da respuestas, de las cuales un $11 \%$ apunta hacia un rol del 
maestro como promotor de valores y como persona íntegra (León y otras 2002).

Las respuestas dejan en evidencia que futuros maestros privilegian lo afectivo, en el proceso enseñanza-aprendizaje, en lugar de la instrucción.

En relación con el perfil real del docente y la docente, los estudios etnográficos de aula, realizados por un equipo interdisciplinario del Instituto de Investigación para el Mejoramiento de la Educación Costarricense, I.I.M.E.C, Universidad de Costa Rica señalan que: los maestros controlan el proceso de enseñanza-aprendizaje cuyo eje es la transmisión de información y conocimientos, esbozados en los programas de estudio y desarrollados con un apego casi total al libro de texto, la metodología generalmente focaliza la repetición y la memorización de contenidos programáticos, los niños y niñas se comportan pasivamente, y se limitan a recibir y repetir conocimiento, tienen gran dependencia del maestro. El docente atiende más al desarrollo cognoscitivo del niño que lo concerniente a las actitudes, a lo psicomotor, a lo social. La creatividad y la reflexión de los niños, están limitadas por las pocas oportunidades que tienen de participar (Campos, 1991).

Observamos en estos hallazgos que los maestros perciben su función docente en la línea de la posición humanista de la educación, pues, dan mayor importancia al afecto en el encuentro humano, docente-estudiante que a su rol de instructor. Sin embargo, en el actuar cotidiano del docente, evidenciamos un proceso enseñanza-aprendizaje de tipo reproductor de contenidos programáticos, controlado por el maestro y con un protagonismo desdibujado del estudiante, proceso poco propicio para enriquecer las relaciones de afecto señaladas por las futuras docentes y los futuros docentes.

El por qué de esta diferencia entre la percepción del futuro maestro y su práctica en el aula, puede ser objeto de estudio en trabajos finales de graduación o en tesis de posgrado en educación.

\section{Ausencias en la misión del docente}

Nos interesa hacer notar en este artículo que en ambas visiones: la de los futuros docentes, y la de aquellos que no ejercen su profesión en las aulas no se menciona o se hace la ansiada búsqueda del conocimiento, al descubrirlo, construirlo, y compartirlo en la realidad de su aula, de su comunidad o en la virtual tan en boga hoy en día. Lamentablemente, no se vislumbra la manera en que docentes y estudiantes encontremos sentido a lo que enseñamos y aprendemos. Pues no trascendemos a crear los espacios en el aula, para criticar aspectos que afectan nuestra dignidad o aquellos en los cuales no creemos porque tenemos duda de que sean verdades infalibles. Las ausencias citadas indican que tenemos una misión en la transformación del rol del docente, es por ello que los formadores de docentes tenemos la responsabilidad de la autorreflexión sobre nuestro quehacer y a partir de su fruto debemos planificar con una orientación que conduzca a los docentes a develar, conocer, analizar y, en la medida de lo posible, transformar la realidad educativa. Es aquí, donde la alternativa de formar docentes investigadores nos aporta una forma de vivenciar el proceso educativo de una manera diferente, pues se potencia al ser humano a descubrir, a reflexionar, a actuar, a crear e innovar.

\section{El docente investigador: la visión del mundo que lo rodea}

En aras de formar ese docente investigador, nos ubicamos en la concepción del mundo de la vida de los pensadores Schütz y Harberma (Berticelli, 2000), en donde se da importancia a la naturaleza simbólica del ser humano, a su experiencia 
comunicativa e intersubjetiva, a sus diferentes verdades, reales en sus mentes y corazones y en su actuar, las que libremente deben aflorar en la acción educativa de las personas. De manera que a partir de ella, construyan su mundo de vida. Ese mundo que Mahatama Gandi llamó "el planeta que tiene lo suficiente para satisfacer los deseos de todos, pero no su codicia" citado por Rodrigo Carazo (2002).

Esta concepción de mundo, me lleva a situarme en los paradigmas curriculares práctico y emancipador (Grundy, 1991), los cuales se sustentan en la comprensión profunda del fenómeno educativo y en la liberación del ser humano, de un mundo del sistema (Berticelli, 2000) caracterizado por su materialismo, aquí se privilegia la producción económica, y se violenta la simbólica, se ejerce el control y la imposición y se dinimizan los procesos que valoran la experiencia comunicativa intersubjetiva. En consecuencia, las verdades de las élites de poder ahogan los valores culturales, los afectos, las construcciones e idearios propios de los pueblos. Un mundo que controla y regula objetos, cosas, para lo cual emplea la ciencia empírico-analítica (Kemmis, 1993).

El mundo de la vida y los paradigmas curriculares práctico y emancipador buscan una educación cuya calidad se valora por la pertenencia de sus procesos de observación, de participación, de construcción de conocimiento, de actitudes creativas e innovadoras que den respuesta a los problemas nacionales y de la región centroamericana relacionados con la ecología, el deterioro social, el tratamiento de temas de género, discapacidad, diversidad cultural y étnica. Sin embargo, contraria a la calidad del mundo de la vida; la educación se inclina hacia una calidad acartonada, que da relevancia a las notas, a los promedios, a los títulos, a los costos y a los beneficios económicos; todo ello congruente con el mundo del sistema que los autores antes citados, caracterizan como materialistas. $\mathrm{Al}$ respecto señala Rodrigo Carazo, "Falta mucho por hacer" y agrega: “...pero somos conscientes de que, si al ser humano, se le coloca siempre, como centro de la creación, estaremos acercándonos a las metas superiores que desea una sociedad de verdad civilizada" (Carazo, 2002).

Para aproximarnos, aún más, a esbozar los rasgos que un docente investigador requiere, la investigación educativa y el paradigma cualitativo aportan los conocimientos teórico-prácticos adecuados, pues permite a las docentes investigadoras: observar la realidad educativa de forma natural y espontánea, recontruirla para comprenderla y, si es posible, transformarla, en cuyo proceso, los docentes y las docentes indagamos, conjuntamente con los estudiantes nuestra práctica diaria en el aula.

\section{Rasgos del docente-investigador}

Finalmente y después de plantear la génesis teórica del docente ofrecemos, a continuación, algunas características de la docente investigadora:

- $\quad$ Ejerce el poder para ayudar al estudiante, y no se ampara en el poder de su saber para realizar la labor docente.

- Analiza continuamente su proyecto de vida personal y profesional consciente de sus limitaciones, fortalezas, carencias, miedos, ideales, incertidumbres y sueños, de manera que aprenda de sí mismo y oriente el aprendizaje de estudiantes de la misma forma.

- Construye una práctica docente congruente con su posición ante el mundo. En palabras de Antonio Pérez Esclarin (1997), “...uno explica lo que sabe o cree saber; pero orienta el aprendizaje de sus estudiantes con lo 
que es..." Si el docente-investigador es inquisitivo, comprometido con sus estudiantes y la sociedad, formará docentes en esa línea.

- Elabora el discurso educativo todos los días, al observar e indagar la realidad y destierra el discurso vago y superficial. Esclarin acota al respeto "escudriña el barro de nuestra realidad y construye a partir de ella”. Es decir, da significado y calidad a la formación docente.

- $\quad$ Abre caminos, no receta fórmulas, ello implica aventura, riesgo, incertidumbre, ilusiones y desilusiones, aciertos y desaciertos, como la vida misma.

- $\quad$ Entrega sus propios ojos, sus vivencias, sus conocimientos para que los estudiantes investiguen la realidad con ahínco y profundidad, en un afán de entenderla, sin condenarla, y así buscar las acciones pertinentes para mejorarla.

- Construye teorías respetando el vientre cultural de dónde provienen, hace énfasis en que éstas no se dan en un contexto neutral y aséptico.

- $\quad$ Construye valores en su continuo indagar en los escenarios educativos y sociales dónde se desenvuelven, no los recita o los proclama, los vive.

- $\quad$ Apuesta a la afectividad hacia sus alumnos, los conoce, los ama, saca lo mejor de ellos, y no reduce su labor a la efectividad y eficacia del producto educativo. Es un filósofo de la educación y no un técnico de ella.

- Lucha contra la rutina, el aburrimiento, el adormecimiento y pone la chispa de la vida al aprendizaje con su actitud inquisitiva y creadora.
- Comparte con los miembros de la comunidad educativa sus construcciones científicas y sus vivencias, al publicarlas, discutirlas en foros, debates u otras actividades de esta naturaleza.

- Forma conciencia crítica para el análisis de políticas, ideologías, paradigmas, enfoques, presentes o tácitos en el discurso y en la práctica.

- Forma con otros docentes investigadores grupos de pensamiento, elabora tendencias educativas pertinentes a su contexto.

- $\quad$ En síntesis, ama y construye el mundo de la vida y destierra aquello del sistema que lo cosifica.

\section{Referencias bibliográficas}

Berticelli, Antonio Ireno. "Alfred Schütz S. Jürgen Habermas: aproximaciones teóricas". Perspectiva Florianopolis. V.18, n³3, p155-189, jan/jun. 2000.

Campos, Saborío Natalia, "Estilos de enseñanza. Aprendizaje en aulas de escuelas ubicadas en zonas urbanomarginales". Revista Educación 15 (2) 34- 47, 1991. Editorial de la Universidad de Costa Rica.

Carazo, Odio Rodrigo. Rodrigo Carazo con la dignidad en las venas. Ediciones el Castillo. Cartago. Costa Rica. 2002.

Grundy, Shirley. Producto o Praxis del Curriculum. Ediciones Morata S.A. Madrid, 1987.

Kemmis, Stephen. El curriculum, más allá de la teoría de la reproducción. Ediciones Morata, S.L., Madrid, 1993. 
León Saénz, Ana Teresa y otras. "Validación de un módulo de selección de candidatos a docentes". Revista Centroamericana de Educación. Vol. 1, número 1, 2002. Taller Gráfico Impresora Obando, San José Costa Rica.

León Saénz, Ana Teresa y otras. Proyecto. "Validación de un módulo de selección de candidatos a docentes". Coordinadora Educativa Cultural (C.E.C.C) Centro de Investigación y docencia (C.I.D.E). Universidad Nacional, Octubre, 2002.

Pérez, Esclarín Antonio. "El docente necesario". Movimiento Pedagógico. Año V. N¹4, Venezuela. Junio, 1997.

Natalia Campos Saborío Investigadora del Instituto de Investigaciones para el Mejoramiento de la Educación Costarricense de la Universidad de Costa Rica (IIMEC) 